\title{
The Principles of Sustainable Development as a Form of Structural Transformation
}

\author{
Sergey Zhironkin ${ }^{1,2,}{ }^{*}$, Andrey Voloshin ${ }^{1}$, Olga Zhironkina ${ }^{3}$, Stefan Vöth ${ }^{4}$, and Gennady \\ Kayachev $^{1}$ \\ ${ }^{1}$ Siberian Federal University, 660075 Lida Prushinskaya St. 2, Krasnoyarsk, Russia \\ ${ }^{2}$ T.F. Gorbachev Kuzbass State Technical University, 650000 Kemerovo, 28 Vesennya st., \\ Kemerovo, Russia \\ ${ }^{3}$ Kemerovo State University, 650043, 6 Krasnaya St., Kemerovo, Russia \\ ${ }^{4}$ Technische Hochschule Georg Agricola, Centre for Drive and Lifting Technology ZAFT, Bochum, \\ Germany
}

\begin{abstract}
Sustainable development today covers not only certain aspects of the environmental and economic aspects of society. The very structure of the economy, in particular the production sphere, as well as the whole society, is changing radically. Moreover, the structure is not only a systemological, but also the category of sustainable development. It acts as the basis of any material phenomenon or process, that is, it serves as a relatively stable basis on which more mobile elements function. Therefore, the closest concept that allows revealing the essence of sustainable development, the problem of cognition of environmental and economic transformations, transformations and their regulation, is the structure. It is by using the disclosure of the structure as a fundamental element of the system of sustainable development that can reveal the factors of deep changes in the economy, under the influence of which the transformation of industry towards modern environmental guidelines, and with it employment, investment, innovation, systems of their state regulation.
\end{abstract}

\section{Introduction}

The growing need for the transition to sustainable development for the Russian economy is due to both the crisis processes in the field of ecology in recent years and the constraining role that structural problems play in promoting environmental values, in establishing a postindustrial way of life, and in improving the quality of life. In turn, an analysis of the principles of structural regulation of the transition to sustainable development is important for the formation of its theoretical foundations, taking into account national characteristics and forms of their implementation. The essence of the concept of "principle" reveals its Latin meaning - the beginning, the foundation (principium), on which theory, economic policy, etc. can be built. As a scientific category, principles are on a par with such components of a scientific methodology as approaches, economic categories, and laws.

\footnotetext{
* Correspondent author: zhironkinsa@,kuzstu.ru
} 


\section{Materials and Methods}

Representatives of classical political economy, in particular, A. Smith [1], were one of the first principles to regulate the economy: non-interference by the state in the functioning of the national economy, the action of the "invisible hand" of the market.

K. Marx [2] highlighted the general methodological principles of the study of categories of economics, thereby laying the foundation for the study of processes and phenomena in the development of economic relations, their structure and forms of implementation in economic practice.

The first principle is a dialectical one, according to which within any economic phenomenon there is an internal contradiction that constitutes the source of its own development. The structure of the national economy here also cannot be an exception, since it is a clearly defined category, which implies the presence of mutually penetrating and mutually exclusive opposites in it. From this general proposed by K. Marx for the analysis of all economic phenomena of the principle, it is advisable to single out a number of particular principles applicable to the structural regulation of the economy:

- the continuity of changes in the structure of the economy and, accordingly, the permanent need for its regulation for sustainable development;

- conditionality of structural changes by objective factors (such as scientific and technological progress, development of property relations, the emergence of new forms of economic relations). Therefore, structural regulation should affect not only quantitative indicators of economic development (reproduction, macro-dynamic), but also qualitative ones, which are associated with the pre-formation of economic relations as a result of the accumulation of gradual quantitative changes;

- the non-absolute nature of economic dynamics as a criterion for determining the directions, forms and results of the structural regulation of the economy, since its development is not a repetition of cycles, but progressive movement along an ascending line. Therefore, in the development of structural regulation, it is necessary to be guided not only by economic growth, but also by the development of economic relations and institutions.

The second principle is the correspondence of production relations to the nature and level of productive forces, which are sides of each production method. Consequently, highlighting the technological modes in the structure of the economy (as the dominant ways of producing a social product), it is impossible to focus only on the branching productive forces that form them (according to K. Marx, means of production and people who have certain production experience, labor skills and bringing these means of production into action). It is necessary to analyze whether the level of development of economic relations corresponds to the desired mode.

By detailing the principle of dialectical correspondence of production relations and productive forces in relation to sustainable development, we believe that the impact on the structure in order to develop a certain order (in our case, the fifth and sixth) requires not only the development of the required high-tech industries, but and improving economic relations. This should affect both the areas of ownership, investment and credit, the distribution of the cost of the finished product and income, as well as the distribution of people in the structure of industry. The latter echoes the Keynesian idea of a change in the structure of consumption, which should correspond to structural changes in the production of a gross domestic product [3].

Thus, the Marx principles of the analysis of economic phenomena and their regulation are generally methodological, their value is that they are applicable for sustainable development. At the same time, the principles of neoliberal regulation of the economy, put forward and substantiated by proponents of modern neoliberalism, are more detailed. 
L. Erhard, as a vivid representative of this area of economic science, continued the development of the classical principles of economic regulation, adapting them to the realities of the transition to sustainable development. Unlike the classical school, neoliberalism is based on the idea of priority of free competition, but not contrary to, but as a consequence of the state's impact on the economy. Neoliberals see the role of state stress in the regulation of the economy in the functions of the "night guard" or "sports judge". The credo of neoliberalism was succinctly expressed by L. Erhard: "Competition is wherever possible; regulation is where it is necessary" [4]. Therefore, the basic principles of neoliberal impact on the economy include:

- liberalization of the economy, that is, ensuring the minimum necessary intervention in it; - the need for state regulation of the transition to sustainable development, as well as the use of principles of free pricing;

- priority of private property and free markets, interference in which by the state is permissible only in extreme cases (war, catastrophes, cataclysms).

In contrast to the neoliberal, the basic principles of Keynesian economic regulation include the following.

The first principle is that the main (but certainly not the only) regulator of the modern market economy is not the market, but the state. Consequently, regulatory actions that are significant for the economy are formed not at the micro, but at the macro level, and take into account national goals and interests. The impact itself is not only on intercompany relations, but also on the interconnections between "state-firms" and "firms-households". The state becomes the leading subject of the national economy, endowed with its property. Therefore, we can distinguish from Keynesian provisions the principle of structural regulation of the economy that is significant for us, which consists in the interaction of its public and private sectors. This interaction should develop in the following areas: nationalization and privatization of property in industry, in the infrastructure and financial sectors; the creation of state-owned companies in the latest industries, concentrating the sixth technological structure; tax incentives for environment management innovation.

The second principle is the planned and predictive nature of regulation, formed on a scientific basis and significantly reducing the impact of market forces on the development of the national economy. Therefore, in relation to the structural regulation of the economy, we emphasize the importance of the principle of indicative planning and forecasting impact of the state on the economy.

The third principle of Keynesian economic regulation is the implementation by the state of a policy of "effective demand". The central task of the state, according to J.M. Keynes, is to ensure high volumes of "effective demand" (that part of total expenditures, which is determined by the tendency of households to increase their consumption as income grows instead of increasing savings) [3]. It is important for us that the implementation of the principle of regulation of "effective demand" allows us to influence the structure of investments and innovations, and to change the proportions of the output of consumer goods and means of production.

Institutionalists (J. K. Galbraith [5], D. North [6], and others) classify the principles of economic regulation into basic and derivatives.

Basic principles: coordination of economic interests of subjects of entrepreneurship; ensuring the unity of law enforcement, coercion and control by the state over the mandatory implementation of institutional regulations; compulsory fulfillment of contractual obligations; the organization of the economic order and the responsibility of the state for the establishment of general "rules of the game" for business entities;

Derivative principles: an informed choice of strategies for the development of market entities that contribute to improving the efficiency of production and distribution of goods; 
guarantees of institutional conditions for the rapid adaptation of firms to the market environment; preferred attitude to efficiently functioning business entities; implementation of entrepreneurial activity within the established norms and rules.

The principles discussed above are mainly associated with the knowledge of economic laws and phenomena, as well as with the regulation of the entire system of transition to sustainable development as a whole [7-8]. Fundamental issues of the development of the structure of the national economy are considered in the framework of the system-structural and system-self-organization approaches [9]. In general, their basic principles include:

- principles of consistency and isomorphism of the system of the national economy. These principles reflect a universal view of the economy as a system with all its inherent laws, as well as the conformity of the structure of subsystems to the structure of the "head" system;

- the principle of dissipation, which consists in the fact that from the totality of admissible states of the system under the influence of the regulatory action, one is realized that corresponds to a minimum increase in entropy (disorder) [10-11];

- the principle of the presence of an attractor (the desired state of the system and its structure, to which the system should strive in its development);

- the presence in the structure of the system of "catalysts" for its development - factors directing the economy to the most winning attractors [12-14].

\section{Results and Discussion}

Thus, we are dealing with a fairly wide range of principles that form the basis of approaches to regulating the economy in the transition to sustainable development. Therefore, the starting point for highlighting the principles of structural regulation of the transition to sustainable development is the division of the existing principles of the functioning and regulation of the economy (as applied to its structure) into the following parts:

1. The principles of analysis of the structure of the economy: the priority of content over form; consideration of environmental factors; unity of theory and practice; the dialectical principle, which implies the development through movement and resolution of contradictions; inequality of economic dynamics as a criterion of structural analysis of the economy.

2. The principles of functioning of the structure of the national economy: systemicity and isomorphism, synergy and informatization; conditionality of structural changes by objective factors; the continuity of structural changes and the permanence of the need for their regulation; correspondence of production relations to the nature and level of productive forces; proportionality between resources and needs; compliance of the institutional structure of society with the technological structure of production; the presence in the structure of the economic system of the attractor and catalysts for its development.

3. The principles of regulation of the structure of the economy in the transition to sustainable development:

- keynesian principles: the initiating and regulatory role of the state, the priority of the state (and not the market) in regulating the structure of the economy, the planned and predictive nature of such regulation;

- institutional principles: state responsibility for the establishment of general "rules of the game"; coordination of the economic interests of business entities and the "cultivation" of the necessary institutions in the structure of the economy;

- the neoliberal principle: the transfer of structural changes in the monetary system to the structure of the country's economy;

- principles of a systematic self-organization approach: functionality and dissipation. The last principle contradicts the classical principles of regulation - the state's non-interference in the functioning of market entities, the "invisible hands", the use of which in structural regulation 
will inevitably increase entropy in the system of the national economy. As a result, structural changes will be unpredictable, disorganization.

It is these principles that should become the basis for determining the theoretical content of the structural regulation of the economy in the transition to sustainable development. It is advisable to add a number of principles to them, allowing to more fully reveal the essence of sustainable development.

The first of these is multilateralism, the complexity of structural regulation, which should include:

- normative regulation (by improving the legal framework, technical, financial, environmental, environmental standards, etc.);

- indicative target-oriented regulation (development and adoption of target plans and programs for the development of the green economy, reduction of consumption of non-renewable resources, transition to alternative energy, etc.);

- market regulation (creation of conditions for inter-industry capital flow, development of a competitive environment, equalization of inter-regional disparities, intensification of entrepreneurial activity in the innovation sector).

The second principle is the phasing of structural regulation. From the perspective of a systematic understanding, the development of structural regulation of the economy (both in theory and in practice) requires a consistent solution to the following key problems.

The first is the identification of various criteria for structuring the national economy and the types of structure, the identification of objects, subjects, and the subject-targeted area of transition to sustainable development.

The second is the determination of the effective directions of the structural regulation of the national economy, based on an analysis of the links between its structure, forms of economic relations and the characteristics of the transition to sustainable development. It is important for the Russian economy to take into account the interconnections between its market transformation and the transition to sustainable development, since market reforms impose qualitatively new requirements on the structure of the economy, and environmental problems hamper the integration processes with technologically advanced countries.

The third principle of structural regulation of the economy that we propose is the correspondence of its forms and tools to the level of problems of transition to sustainable development. In particular, the huge technological lag of Russia from developed countries, the extremely low pace of formation of the newest - the sixth - technological layer in the country's economy is due to the lack of a whole range of economic relations, institutions, and effectively interacting economic entities. Therefore, their formation requires the adoption of not only economic incentives, but also direct regulation of R\&D and innovation. And the regulation of the structure of exports and imports as a "derivative" of the manufacturing sector should be carried out primarily by economic methods, avoiding excessive protectionism, which generates raw materials rent-oriented and dependent trends among domestic enterprises

\section{Conclusion}

Thus, the study of approaches to determining the principles of revealing the structural problems of the national economy during the transition to sustainable development made it possible to divide them into principles of analysis, functioning and regulation of its structure (Keynesian, institutional, neoliberal, systemic self-organization). In addition to them, we proposed the principles of multilateralism and complexity, the phasing of structural regulation of the economy, as well as the principle of the conformity of its forms and tools to the level of environmental problems. The implementation of these principles is designed to help accelerate the transition to sustainable development. 


\section{References}

1. E. A. Benians, Camb. Hist. J., 1, 249 (1925)

2. U. Kozo, Principles of Political Economy. Theory of a Purely Capitalist Society (Harvester, Brighton, 1980)

3. B. Bateman, The return to Keynes (Harvard University Press, Cambridge, 2010)

4. V. R. Berghahn, Eur. Rev. Int. Stud., 2:3, 37-47 (2015)

5. J. K. Galbraith, Longtime Economics (Harvard University Press, Cambridge, 2006)

6. D. North, Am. Econ. Rev., 55:1/), 86-91 (1965)

7. E. Dotsenko, N. Ezdina, E3S Web Conf., 41, 04048 (2018)

8. E. Dotsenko, N. Ezdina, S. Mudrova, E3S Web Conf., 41, 04050 (2018)

9. M. S. Zlotnikov, V. V. Telnykh, S.I . Mutovin, S. K. Demchenko, J. J. Suslova, Journal of Environmental Management and Tourism, 8:2, 366-372 (2017)

10. O. Kalenov, S. Kukushkin, R. Kamanina, E3S Web Conf., 105, 04028 (2019)

11. S. Kukushkin, O.Kalenov, E3S Web Conf., 105, 04022 (2019)

12. I. A. Kudryashova, E. A. Kharlampenkov, N. V. Zakharova, Izvestiya Ferrous Metallurgy, 61:11, 914-919 (2018)

13. I. Kudryashova, E. Kharlampenkov, A. Kolevatova, N. Zakharova, E3S Web Conf., 41, 02025 (2018)

14. I. Kudryashova, N. Zakharova, E. Kharlampenkov, E3S Web Conf., 21, 02016 (2017) 